\title{
Serial measurement of circulating immune complexes in myocardial infarction
}

\author{
EVA SZONDY, ZSUZSA MEZEY, G FÜST, JUDIT SZÉKELY, S GERÖ \\ From the Arteriosclerosis Research Group of the Ministry of Health, Ist Medical Department of István City-Hospital, \\ and IInd Medical Department of Korányi City-Hospital, Budapest, Hungary
}

SUMMARY To study the changes in the quantity of circulating immune complexes in myocardial infarction two serial investigations were performed in 45 and 63 patients, respectively. For the detection of circulating immune complexes in the first series, two methods, a complement consumption test and a Clq-solubility test were used. In the second series, a polyethylene glycol (PEG)-precipitation assay was added to these methods.

The incidence of circulating immune complexes was studied on the first, third, seventh, 14th, and 21 st day. On the first day the complexes were detected in $59 \%$ of the patients. Their occurrence increased in the further samplings to $77 \%$, but from the seventh day their concentration decreased and on the 21 st day they were detected in $63 \%$.

Three types of changes in the level of circulating immune complexes could be shown. In type I immune complexes were detected in the first days after the onset of the infarction, then, after a gradual decrease, the results became negative. In type II immune complexes appeared in the second to third week and their quantity did not alter during the entire observation period. In type III the circulating immune complexes could be detected throughout the whole period of the study.

These changes in their concentration were frequently associated with the clinical course of the disease.

There is much evidence that immune complexes are involved in the development of inflammatory lesions in various organs of patients, ${ }^{12}$ and in experimental animals. ${ }^{34}$ It has also been shown that they can be deposited in the vascular wall as well. ${ }^{5}$ Indeed it has also been suggested by Mathews et al..$^{6}$ that immune complexes are circulating in the blood of arteriosclerotic patients and that these complexes play a role in the pathogenesis of vascular diseases.

In our previous work ${ }^{7}$ we have reported that circulating immune complexes could be detected in the sera of patients with vascular diseases. The highest incidence (38\%) of such complexes was found in patients with myocardial infarction. Our previously published results concerning the occurrence of these immune complexes in vascular diseases were confirmed by Farrell et al. ${ }^{8}$

In our present study we have serially examined the changes in the concentration of these complexes in patients with myocardial infarction from the first day of the onset of the infarction until the end of a three week period of observation.

Received for publication 14 November 1980

\section{Subjects and methods}

PATIENTS

Sera of 108 patients, 69 male and 39 female, aged from 30 to 86 (mean 63 years) were investigated. The diagnosis was based on laboratory findings, electrocardiographic abnormalities, and typical clinical course. In nine patients the diagnosis was also confirmed by necropsy.

\section{BLOOD SAMPLINGS}

In the first part of our investigations (45 patients) blood samples were taken on the first three days after infarction and thereafter weekly.

In the second series (63 patients) blood samples were taken on the first, third, and seventh days of the disease, and then weekly.

\section{METHODS FOR DETECTION OF IMMUNE COM PLEXES}

(1) Complement consumption assay

This assay was performed as outlined by Johnson et al. ${ }^{9}$ with some modifications. ${ }^{7}$ Briefly, $0.1 \mathrm{ml}$ heat-treated 
$\left(56^{\circ} \mathrm{C}, 60 \mathrm{~min}\right)$ serum of patients or healthy persons was mixed with $0.5 \mathrm{ml}$ diluted freshly reconstituted freezedried guinea pig serum, containing 2.0 to $2.5 \mathrm{CH}_{50}$ units of complement. The required dilution was determined by a previous titration on each occasion. Veronal buffer solution was used as diluent throughout. The mixture of patient's serum and guinea pig serum was incubated at $0^{\circ} \mathrm{C}$ for 60 minutes. Then $0.5 \mathrm{ml}$ of sensitised sheep erythrocyte suspension and $1.5 \mathrm{ml}$ diluent were added, and the samples were further incubated at $37^{\circ} \mathrm{C}$ for 30 minutes. Thereafter the samples were centrifuged to eliminate the non-specific absorbance caused by the colour of the sera studied, supernatants were decanted, and the sediment was lysed by the addition of $3.0 \mathrm{ml}$ distilled water. The haemoglobin content of the lysate was measured spectrophotometrically at $541 \mathrm{~nm}$. With the use of appropriate controls, the complement activity, expressed in $\mathrm{CH}_{50}$ units in each sample, was calculated according to the standard method. The extent of the complement consumption was calculated by the following formula:

$$
\frac{\mathrm{CH}_{50} \text { in control }-\mathrm{CH}_{50} \text { in sample }}{\mathrm{CH}_{50} \text { in control }} \times 100
$$

where control=sample containing $0.1 \mathrm{ml}$ diluent instead of serum.

\section{(2) Complement factor Clq-solubility test}

The test was based on the method of Johnson et al.," but was modified by us for quantitative estimations. ${ }^{7}$ Serum samples were dialysed overnight at $+4^{\circ} \mathrm{C}$ against a $23 \mathrm{mM}$ solution of EDTA ( $\mathrm{pH} 7 \cdot 5$ ). After centrifugation of the dialysed sample at $5000 \mathrm{rev} /$ minute for 30 minutes, the concentration of Clq was measured in the supernatant as well as in the original serum. On each day, the Clq concentration of a control serum (freezedried normal human serum pool) was determined, and a calibration curve was drawn. Each ampoule contained $1 \mathrm{ml}$ serum and was used only once. The Clq contents of both the supernatant and the serum were calculated as a percentage of the control serum, and the extent of the solubility of $\mathrm{Clq}$ was expressed by the following ratio:

\section{Clq concentration in the supernatant}

Clq concentration in the serum.

\section{(3) Polyethylene glycol (PEG)-precipitation test}

This test was performed according to the method of Hašková et al. ${ }^{10}$

Untreated serum samples were stored at $-20^{\circ} \mathrm{C}$ until used. Serum precipitation by PEG was done in $0.01 \mathrm{M}$ borate buffer, $\mathrm{pH} 8.4$ by addition of PEG 6000 solution to human sera prediluted with buffer at $1: 3$, to obtain a final concentration of $3.75 \%$ PEG and 1:30 of serum.
After mixing and 60 minutes incubation at room temperature the mixtures were read spectrophotometrically at $450 \mathrm{~nm}$ against the same concentration of the given serum in buffer only and the concentration of circulating immune complexes was expressed as $\mathrm{E}_{1 \mathrm{~cm}}^{450}$ values.

Upper limits of normal values (mean+2SD) for the three assays were determined in the sera of 59 healthy blood donors. In the complement consumption test consumption of $15 \%$ or more of the available complement activity was considered as a positive result. The Clq-solubility test was considered to be positive when the ratio of Clq content of the supernatant of the serum dialysed against low ionic strength-EDTA buffer to that found in the untreated serum was $\mathbf{0 . 2 8}$ or higher. In the PEG-precipitation assay an optical density of 0.040 or more was considered as positive.

\section{METHODS FOR MEASUREMENT OF AST(SGOT) VALUES}

AST was measured according to the colorimetric method of Reitman and Frankel. ${ }^{11}$ and was considered to be positive when the values were higher than 19.3 $\mathrm{U} / \mathrm{l}$.

The correlation between the AST values and the concentration of circulating immune complexes was calculated on the basis of the values obtained in the first days after the heart attack.

\section{STATISTICAL ANALYSIS}

Spearman's rank correlation method was used for the estimation of the correlation coefficient between the results of the different assays. Correlation between the occurrence of circulating immune complexes and the AST values was calculated by the same test.

\section{Results}

(1) In the first part of our serial investigations sera of 45 patients with myocardial infarction were studied with the complement consumption test and the Clqsolubility test. In 24 cases negative results were obtained during the whole period of the study. Positive results were found in the sera of 21 patients. In the quantitative changes of circulating immune complexes three types could be observed (Fig. 1). In type I (nine patients) immune complexes could be detected in the first days after the infarction. Then, after a gradual decrease, the results became negative. In type II (six patients) the immune complexes appeared in the second to third week and their concentration did not change during the rest of the further observation period. In type III (six patients) circulating immune complexes were found throughout the whole period of the study.

(2) In the second series of our studies the concentration of circulating immune complexes was examined 

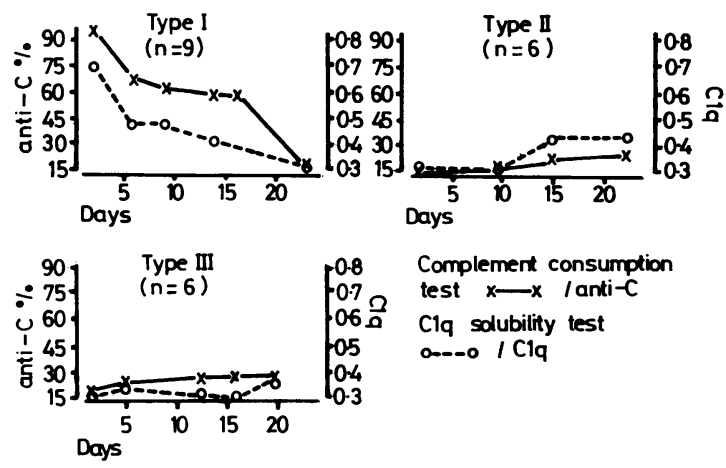

Complement consumption test $x-x$ lanti- $C$ Clq solubility test on--o I Clq

Fig. 1 Changes in the level of circulating immune complexes in myocardial infarction.

with all three tests in 63 patients. Using these tests the three types of changes in the level of circulating immune complexes could also be shown. Twenty-eight cases were of type I, 16 cases of type II, and 19 cases of type III.

Table 1 Occurrence of circulating immune complexes in myocardial infarction

\begin{tabular}{llllll}
\hline & Ist day & 3rd day & 7th day & 14th day & 21st day \\
\hline Negative & 26 & 16 & 14 & 16 & 23 \\
Positive in one test & 27 & 31 & 32 & 29 & 27 \\
Positive in two tests & 9 & 13 & 17 & 18 & 12 \\
Positive in three tests & 1 & 3 & - & - & 1 \\
Positive total & $37(59 \%)$ & $47(74 \%)$ & $49(77 \%)$ & $47(74 \%)$ & $40(63 \%)$ \\
\hline
\end{tabular}

The incidence of circulating immune complexes in the patient's sera was tested on the first, third, seventh, 14th, and 21st day. In Table 1 it is shown that on the first day the circulating immune complexes could be detected altogether in $59 \%$ of the cases. The incidence of circulating immune complexes increased at the further serum samplings performed on the third and seventh day. We have found circulating immune complexes in 74 to $77 \%$ of the patients investigated. In the samples taken on the 21 st day of the disease the incidence of circulating immune complexes decreased to $63 \%$.

Positive results with at least two assays were found on the first day in 10 patients $(16 \%)$, by the third day in
16 patients $(25 \%)$, on the seventh and 14 th day in 17 patients $(27 \%)$, and on the 21 st day in 13 patients (21\%).

No correlation was found between the incidence of circulating immune complexes and the maximum AST values detected in the first few days of the disease (Tables 2 and 3 ).

In 21 patients with subendocardial infarction and in 26 patients with transmural infarction the correlation between the depth of the myocardial damage and the occurrence of the circulating immune complexes was also studied. No significant differences were found between the two groups (Table 4).

Next some cases arranged into two groups will be discussed individually.

\section{(1) PATIENTS WITH MYOCARDIAL INFARCTION WITHOUT ANY COMPLICATIONS}

In patient PJ (Fig. 2) in the first week after the heart attack circulating immune complexes were detected with all the three methods used by us. After a gradual diminution in the third week only the Clq-solubility test remained positive.

Table 2 Correlation between maximal AST values and occurrence of immune complexes

\begin{tabular}{|c|c|c|}
\hline$A S T(U / l)$ & Negative $(n=I I)$ & Positive ( $n=55)$ \\
\hline $\begin{array}{l}\text { (a) Detected } \\
\text { First day } \\
\text { Third day }\end{array}$ & $\begin{array}{l}9(82 \%) \\
9(82 \%)\end{array}$ & $\begin{array}{l}27(49 \%) \\
40(73 \%)\end{array}$ \\
\hline $\begin{array}{l}\text { (b) Detected } \\
\text { First day } \\
\text { Third day }\end{array}$ & $\begin{array}{l}1(9 \%) \\
5(45 \%)\end{array}$ & $\begin{array}{l}11(20 \%) \\
13(23.6 \%)\end{array}$ \\
\hline
\end{tabular}

Table 4 Positive results in tests used for detecting circulating immune complexes in patients with myocardial infarction with different localisation

\begin{tabular}{lll}
\hline & $\begin{array}{l}\text { Transmural } \\
\text { infarction } \\
(\boldsymbol{n}=36)\end{array}$ & $\begin{array}{l}\text { Subendocardial } \\
\text { infarction } \\
(\boldsymbol{n}=27)\end{array}$ \\
\hline First day & $19(52 \%)$ & $18(66 \%)$ \\
Third day & $25(69 \%)$ & $22(81 \%)$ \\
Seventh day & $28(77 \%)$ & $21(77 \%)$ \\
14th day & $29(80 \%)$ & $18(66 \%)$ \\
21st day & $24(66 \%)$ & $16(59 \%)$ \\
\hline
\end{tabular}

Table 3 Correlation between AST values and concentration of circulating immune complexes in early stage of myocardial infarction

\begin{tabular}{|c|c|c|c|c|c|c|}
\hline \multirow{2}{*}{$\begin{array}{l}\text { Test used for immune } \\
\text { complex measurement } \\
\text { Day after infarction } \\
\text { Correlation coefficient } \\
\text { p }\end{array}$} & \multicolumn{2}{|c|}{$\begin{array}{l}\text { Complement consumption } \\
\text { assay }\end{array}$} & \multicolumn{2}{|c|}{ Clq-solubility test } & \multicolumn{2}{|c|}{$\begin{array}{l}\text { PEG-precipitation } \\
\text { test }\end{array}$} \\
\hline & $\begin{array}{l}\text { First } \\
0.229 \\
>0.1\end{array}$ & $\begin{array}{c}\text { Third } \\
0.272 \\
>0.1\end{array}$ & $\begin{array}{l}\text { First } \\
-0.256 \\
>0.1\end{array}$ & $\begin{array}{l}\text { Third } \\
-0.366 \\
>0.1\end{array}$ & $\begin{array}{l}\text { First } \\
0.292 \\
>0.1\end{array}$ & $\begin{array}{c}\text { Third } \\
0.075 \\
>0.1\end{array}$ \\
\hline
\end{tabular}




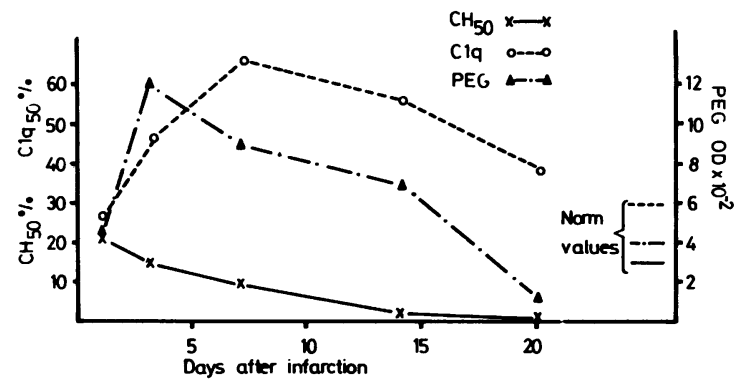

Fig. 2 Circulating immune complexes in patient PF.

Patient DM (Fig. 3) was admitted to hospital with symptoms of angina pectoris. No circulating immune complexes could be detected in her sera. In the second week her condition worsened and on the 15th day myocardial infarction was diagnosed. Parallel with the onset of the infarction the complement consumption test and some days later the Clq-solubility test also became positive.

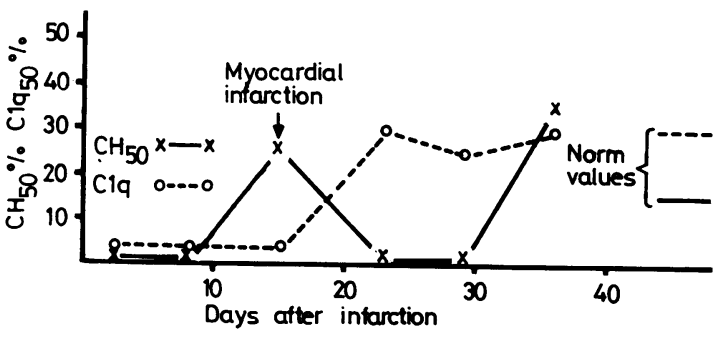

Fig. 3 Circulating immune complexes in patient DM.

(2) CASES IN WHICH, IN ADDITION TO MYOCARDIAL INFARCTION, COMPLICATIONS DEVELOPED

In the sera of patient BA (Fig. 4) the complement consumption test was negative and the Clq-solubility test remained positive during the whole observation period. In the first week after the onset of myocardial infarction the PEG-precipitation test was positive and

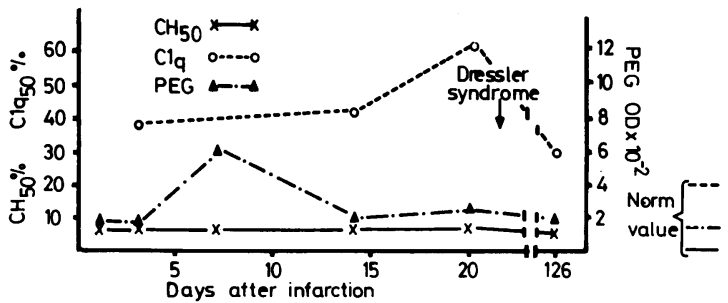

Fig. 4 Circulating immune complexes in patient $B A$.

on the 14th day it returned to normal values. During the third week an increase in the concentration of circulating immune complexes was detected by the Clq-solubility method and on the 21st day the clinical signs of a Dressler syndrome were diagnosed. After three months the quantity of circulating immune complexes detected by all the three methods had become negative.

In the case of patient KR (Fig. 5) the Dressler syndrome was also considered as a result of clinical observations. It can be seen that from the 14th day the increase in the concentration of circulating immune complexes detected by the PEG-precipitation method was presumably associated with this complication.

In several patients some other accompanying complications, for example thrombosis, acute bronchitis, pulmonary embolism, etc, were also frequently followed by the increase in the concentration of circulating immune complexes.

Poor correlations were observed between the results of the different assays used for the detection of circulating immune complexes. Correlations between the complement consumption test and the PEG-precipitation test, or between the PEG-precipitation assay and the Clq-solubility test were not significant $(\mathrm{r}=0.125$ and 0.038 , respectively; $p>0.5$ in both cases). Correlation between the complement consumption test and the Clq-solubility test was of borderline significance $(0.05<\mathrm{p}<0 \cdot 1 \mathrm{r}=0.208)$.
Fig. 5 Circulating immune complexes in patient $K R$.

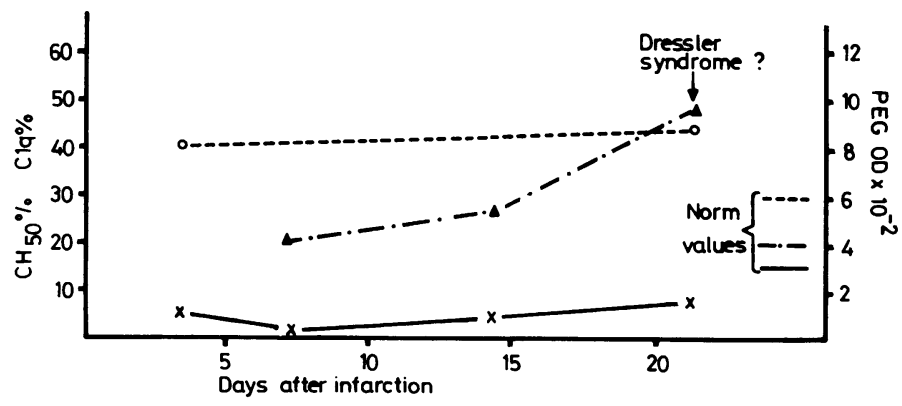




\section{Discussion}

Tests for circulating immune complexes were performed for three weeks in two series of patients with acute myocardial infarction. In the first series two tests were used, in the second three.

When the positive tests were studied over the three weeks in relation to the clinical course of the disease, that relation was found to be variable. In many instances, however, there did seem to be a clinically significant correlation.

In series 1 , the tests were wholly negative in 24 out of the 45 patients, but in series 2 in all of the patients studied, at least one test for these circulating immune complexes was positive at some point in the period. This difference could be explained by two facts:

(1) In the first week, when the circulating immune complexes were found to be highest, two samples were tested in the first series, whereas three samples were studied in the second.

(2) The PEG-precipitation test, applied only in the second series, had a relatively high sensitivity and did not correlate with the other two assays.

In the changes of the level of circulating immune complexes three types could be distinguished. In type I they were detected in the early period of the infarction and after a gradual decrease they were eliminated from the serum. At present we cannot exclude the possibility that immune complexes are formed from autoantibodies present in the sera of the patients and antigens released from the destroyed heart tissue. In this case their formation can be considered as a consequence of the myocardial necrosis. Our finding, however, that there was no correlation between the incidence of circulating immune complexes and the AST values does not support this assumption.

On the basis of these observations in some cases a primary effect of the circulating immune complexes may be supposed. It would be necessary, however, to study the preinfarction state in patients with coronary sclerosis before definite conclusions can be drawn.

In type II the increase in the level of circulating immune complexes during the second to third week may be an indicator of a subclinical Dressler syndrome. This suggestion was supported by two clinically diagnosed cases in the present study (Fig. 4 and 5).

In type III the circulating immune complexes were detected during the whole observation period. The permanent high level of circulating immune complexes was possibly caused by the atherosclerotic process itself.

The correlation between the methods used by us was very poor. The correlation coefficient between results obtained by the complement consumption test and the Clq-solubility assay was of borderline significance, as both tests are based on the ability of the immune com- plexes to interact with complement. Between the PEGprecipitation test and the other two assays mentioned above no correlation was found. It has been shown by several authors ${ }^{12-14}$ that the different methods used for the detection of immune complexes are indicating immune complexes with different size of composition, so the results obtained by different methods are not necessarily similar.

Circulating immune complexes may play a signifcant role in the development of the clinical manifestations of arteriosclerosis. Their pathogenic significance, however, can be determined only after the isolation and characterisation of these complexes. Such studies are in progress in our laboratory.

\section{References}

1 Stühlinger WD, Verroust PJ, Morel-Maroger L. Detection of circulating immune complexes in patients with various renal diseases. Immunology 1976; 30: 43-7.

2 Zubler RH, Nydegger U, Perrin LH, et al. Circulating and intra-articular immune complexes in patients with rheumatoid arthritis. $\mathcal{F}$ Clin Invest 1976; 57: 1308-19.

3 Cochrane CG, Koffler D. Immune complex disease in experimental animals and men. Adv Immunol 1973; 16: 185-264.

4 Mannik M, Arend WP. Fate of preformed immune complexes in rabbits and rhesus monkeys. $\mathcal{F}$ Exp Med 1971; 134: $19^{\text {s }}-31^{\mathrm{s}}$.

5 Joffe VI, Zubzinskij JuN, Nagornev VA, Klimov AN. K immunologitscheskoj characteristike eksperimental'nogo ateroscleroza. Biull Eksp Biol Med 1973; 75: 72-6.

6 Mathews JD, Whittingham S, Mackay IR. Autoimmune mechanisms in human vascular diseases. Lancet 1974; ii: 1423-7.

7 Füst G, Szondy E, Székely J, Nánai I, Gerö S. Studies on the occurrence of circulating immune complexes in vascular diseases. Atherosclerosis 1978; 29: 181-90.

8 Farrell C, Bloth B, Nielsen H, Daugharty H, Lundman $\mathrm{T}$, Svehag SE. A survey for circulating immune complexes in patients with acute myocardial infarction. Scand $\mathcal{f}$ Immunol 1977; 6: 1233-40.

9 Johnson AH, Mowbray JF, Porter KA. Detection of circulating immune complexes in pathological human sera. Lancet 1975 ; i: 762-5.

10 Hašková V, Kaslík J, Ríha I, Matl I, Rovenský J. Simple method of circulating immune complex detection in human sera by polyethylene glycol precipitation. $Z$ Immunitaet Forsch Immunobiol 1978; 154: 399-406.

11 Reitman S, Frankel S. A colorimetric method for the determination of serum glutamic oxalacetic and glutamic pyruvic transaminases. Am f Clin Pathol 1957; 28: 56-63.

12 Gabriel A Jr, Agnello V. Detection of immune complexes. f Clin Invest 1977; 59: 990-1001.

13 Rossen RD, Reisberg MA, Hersch EM, Guttermann JV. The Clq binding test for soluble immune complexes. Clinical correlations obtained in patients with cancer. $\mathcal{F}$ Natl Cancer Inst 1977; 58: 1205-15. 
14 Lambert PH, Dixon FJ, Zubler RH, et al. A WHO collaborative study for the evaluation of eighteen methods for detecting immune complexes in serum. $\mathrm{f}$ Clin Lab Immunol 1978; 1: 1-15.
Requests for reprints to Dr Eva Szondy, Arteriosclerosis Research Group of the Ministry of Health, Budapest, Somogyi Béla u 33, H-1085, Hungary. 